\title{
Book Classification Thought and Its Modern Significance in Private Bibliography of Ming Dynasty
}

\author{
Xinning Fang \\ Northwest Normal University, College of Chinese Language and Literature, Lanzhou, Gansu 730070
}

Keywords: Ming Dynasty; private bibliography; Book classification; Modern significance

\begin{abstract}
The Ming Dynasty was a climax of the development of private collection in Chinese history. Both the number of collectors and the number, quality and variety of collections surpassed the previous generation. The prosperity of private book collection has greatly promoted the development of private bibliography. The private bibliographies are a summary of the book collection practice and experience of many years. Many of these excellent methods are still useful for our current book consolidation activities.
\end{abstract}

\section{Book Classification Method in Private Bibliography in Ming Dynasty}

The book classification methods in the private books of the Ming Dynasty mainly include the following aspects. The first is the scientific and practical nature of book classification. The classification of books is not only for better collection, but also for easy searching and use. Therefore, scientific and practical has become a major principle for book collectors to classify books. In the Ming Dynasty, the rulers attached great importance to the compilation of historical books for the sake of political rule and social development, which objectively promoted the prosperity of historical books. The dramatic increase in the number of historical books has made collectors attach great importance to the classification of history books. For example, Qi Chenghan's "Dan Sheng Tang Bibliography" divides history books into 15 categories and 66 subcategories. [1]In addition, he added "Yue Shi" to the department of History, including "Ji Gu Lu", "Da Shi Ji", "Zhi Tong Ji Lue" and books between Official history and unofficial history. Since the Song Dynasty, the number of books about decrees and regulations has been decreasing, Qi Chenghan canceled the books of living notes, and the related books are merged into miscellaneous historical categories. At the same time, he abolished the first-class classification about books such as food and commodities, criminal law, and officials, turning them into secondary categories under the political books.

In addition to the more detailed classification, the Ming Dynasty collectors also attach great importance to the establishment of contemporary history books. The History Department of the "Xu Family Collection Bibliography" established the "The History of the Dynasty" class, recorded 96 kinds of history books. [2]

Others such as "Bai Chuan Shu Zhi", "Shi Shan Tang Collection of Books", "Li Ze Tang Bibliography", etc., have set up the category of contemporary history in the ministry of history, to collect books related to the Ming Dynasty. These meticulous classifications not only objectively reflect the development of books in the Ming Dynasty, but also are very easy to find and read, not only scientific but also practical.

Secondly, it is a free and flexible classification method. From the existing private bibliographies of the Ming Dynasty, there were many ways to classify books at that time, which had the personality of a Book collector. For example, The "Mai Wangguan Bibliography" lists the books in the order of "day", "land", "metaphysics", etc., and belongs to different bookcases. Among them, the "Yu" bookcase is dedicated to the collection of old books of the Song and Yuan Dynasties. [3] The "Xu Family Collection Bibliography" mentioned above, not only separate classification of the history of the dynasty in the Department of History, but also record the works of Ming literati in different regions in "Personal Anthology" category.

Inter-analytic record method and analytic-record method can best reflect the flexibility of book 
collectors in Ming Dynasty. These two methods were used in the bibliography before the Ming Dynasty, but they were only sporadic .In the Ming Dynasty, many private bibliography, such as "Bai Chuan Shu Zhi", " Chao's Bao Wen Tang Bibliography", "Xu's Family Collection Bibliography" and "Xi Sheng Tang Bibliography", have generally used these two methods. Taking " Bai Chuan Shu Zhi " as an example, "Wo Long Anthology" is recorded in the "Anthology of Han, Wei and Six Dynasties" category and "military strategists" category; Han Lin Ce Yao" is recorded in " Novelist " Category and "Personal Anthology " category respectively. Which is the use of Inter-analytic record method ".The "Shen Yin" in "Yua Hua Xuan Shu" in the season of history Department are classified as Hermit books; The article "The Chronicle in period pf Tang Shun Zong" in" Han Changli's Collection of Literature " were taken out and put into the "Qi Ju zhu" of history Department. Which is the use of analytic-record method. [4]The use of these two methods enables books or chapters with interdisciplinary nature to find their place in the corresponding categories for easy access. The book of" Dan Sheng Tang Bibliography" not only uses inter-analytic record method and analytic-record method in many places, but also puts forward a theoretical summary of the two methods in the preface in the bibliography.

Thirdly, it is a classification method that keeps pace with the times. Although the private bibliographies of the Ming Dynasty were mostly compiled for personal retrieval needs, they also reflected the accurately grasping of the development of books by the collectors and the increasingly mature thought of book classification. Following the Song and Yuan Dynasties, popular literature in the Ming Dynasty maintained the momentum of prosperity and development, and the number of related books was also increasing. In the Ming Dynasty, book collectors not only liked to collect such books, but also actively categorized and classified them. Taking opera as an example, the book of" Bai Chuan Bibliography" classifies opera into the category of unofficial history of Department of history. " Chao's Bao Wen Tang Bibliography "set up category of "Yue Fu" to collect the words of the past dynasties. The "Xu's Family Collection Bibliography" sub-division set up the "legendary class", the legend took the original intention of the opera, and the basics included the Zaju and legendary works of the Yuan and Ming Dynasties. It can be seen that in the Ming Dynasty, the knowledge and classification of the opera by the collectors kept moving towards maturity and depth.

In addition, a large number of missionaries came to China in the middle and late Ming Dynasty. They also brought Western science and technology while preaching, and related Western books continued to emerge. Many Western books were recorded in the private books of the Ming Dynasty.For example, the category of western works was set up under the sub-section of the "Mai Wang Guan Bibliography", and nine kinds of writings such as "Qinxi Water Law", "Catholic Essentials" and "Geometry Original" were recorded; "Jiang Yun Lou Bibliography" wrote by Qian Qianyi recorded the Western Learning Books under the category "Evaluation" in Volume II. At the same time, it also added the category about Catholicism including seven kinds of Catholic books such as "Tian Xue Chu Han", "Earthquake Solution" and "Qi Ke".[5] These bibliographies objectively presented the achievements of Western learning at the end of the Ming Dynasty.

\section{The modern significance of book classification thought in private bibliography of Ming Dynasty}

The idea of book classification in private bibliography of Ming Dynasty has a great influence on the collation of books in later ages. First of all, it promotes the scientific and rational classification of books. For example, "Tan Sheng Tang Bibliography" set up the category of "series of books", which was the first time to find a good home for the series. Public and private bibliography of descendants inherits and develops this method. In the Qing Dynasty, "Zhi Sheng Dao Zhai Bibliography ", "Li Shu Chang Zhuo Zun Yuan Bibliography ", "Shu Mu Wen Da bibliographic " and so on all set up category of "Series". During the Period of Jia Qing, Gu Xiu compiled the first series catalogue of books in China - "Hui Ke Bibliography", which contains 261 kinds of catalogues. The "China Books Collection" edited and published by the Shanghai Library from 1959 to 1962 is the largest catalogue of the current department. All these benefits from the exploration of the 
classification of books by private bibliography in Ming Dynasty.

At present, we are in an era of high development and prosperity of books, and book classification is still a problem that librarians and collectors need to think about and explore. Scientific and reasonable classification of books is not only conducive to the preservation and collation of books, but also conducive to the reading and utilization of books, and the real realization of the value of the use of books, which is of great significance to the transmission of culture. At the same time, the compilation and production of book retrieval can help readers find what they need conveniently and quickly in the vast number of books, and meet their needs for book utilization to the greatest extent. Nowadays, with the rapid development of information technology, it also provides great help for the librarians to sort out their books. Therefore, we should carry forward the exploratory spirit of the older generation of book collectors and make due contributions to the preservation and management of books by using advanced scientific and technological means.

Secondly, some classification ideas in the private books of the Ming Dynasty also have important influence on some theoretical cognitions in the book sorting activities of future generations. For example, in book of "Dan Sheng Tang Bibliography ", Qi Chenghan has both the use of the methods of "Inter-analytic record method and analytic-record method, and related theoretical summaries. However, Qi Chenghan's understanding of the definitions, functions and usage methods of the two methods is not deep enough. It was not until the Qing Dynasty that Zhang Xuecheng had a more comprehensive and in-depth understanding and summary of the two methods. Up to now, the "mutual writing method " and "alternative method" still serve as an important theory to guide the book sorting and classification activities.

The continuous exploration of the classification method of books not only facilitates the further scientific and reasonable classification of books, promotes the development of book sorting practice, but also contributes to the development of book classification theory and has positive significance for the construction of book management disciplines. In today's highly developed era of book industry, the use and management of books are becoming increasingly complex and diverse, which requires Book managers to treat the work of book collation with a long-term vision and thinking, and to be good at finding problems in practice and solving problems. Only in constant thinking and exploration can the management of books be continuously refined and scientific and rational, and the theoretical construction of library management can really promote the long-term and healthy development of the practice of book arrangement.

Thirdly, the book collector's love, collection and reading of books, and the book culture thus formed, have important enlightenment significance to the construction of contemporary culture. The Chinese nation is endlessly alive. Five thousand years of civilization need the inheritance and development of generations from generation to generation. The classical literature records that China's vicissitudes of history and self-improvement of national spirit are important carriers of China's long history and culture. Therefore, the protection and inheritance of these documents is precisely to protect the Chinese spirit of the immortality, is to retain our roots, to defend our spiritual home. We should study the spirit of the older generation of bibliophiles, consciously maintain and inherit Chinese culture, have the responsibility and obligation to protect books, promote books, so that the Chinese culture will never be extinct.

Contemporary Chinese society is in a period of rapid development. The quality of life and happiness index of the people are constantly rising. Our cultural pride and confidence are also growing. People are paying close attention to our history and culture with great enthusiasm. They are eager to get relevant information from all kinds of books. Therefore, the arrangement, dissemination and utilization of books must receive the attention of the society. Book managers are important bridges between books and readers, so they shoulder the important task of revitalizing Chinese culture. All kinds of librarians at all levels must attach great importance to the management of books from the history of building Chinese culture, and be good at learning and improving the ability and level of library management from practice, so as to contribute their own strength on the historical stage of building the Chinese Dream.

In short, the prosperity of private bibliography in the Ming Dynasty not only greatly promoted 
the development of book collation practice, but also promoted the theoretical construction of bibliography. The active exploration of book classification by bibliophiles has also inspired the enthusiasm and courage of later generations to participate in book sorting, and has important positive significance for the construction of traditional culture.

\section{Conclusion}

In today's era, the number of books is huge, the form is rich, the variety of books has exceeded any period in history. The sorting and classification of books will also face new situations and problems, and more means and methods should be explored. The excellent book classification thought in the private bibliography of the Ming Dynasty can still provide us with useful reference for today's literature collation, and it still has vitality. The protection of books by the book collectors of the Ming Dynasty and the inheritance of culture left us with a precious spiritual legacy.

\section{References}

[1] Zhong Hua Book Company Editorial Department. Serie of Books about Bibliography from Song, Yuan, Ming to Qing Dynasties. Volume 2 of Ming Dynasty [M]. Beijing: Zhong Hua Publishing House, 2006:139.

[2] Shao Yichen, Shao Zhang. The Revised Edition of Concise Marking of “Si Ku Quan Shu” [M]. Shanghai: Shanghai Ancient Books Publishing House, 1979:353.

[3] Zhong Hua Book Company Editorial Department. Serie of Books about Bibliography from Song, Yuan, Ming to Qing Dynasties. Volume 1 of Ming Dynasty [M]. Beijing: Zhong Hua Publishing House, 2006:883.

[4] Zhong Hua Book Company Editorial Department. Serie of Books about Bibliography from Song, Yuan, Ming to Qing Dynasties. Volume 1 of Ming Dynasty [M]. Beijing: Zhong Hua Publishing House, 2006:707.

[5] Qian Qianyi. Jiang Yun Lou Bibliography [M].Beijing: Zhong Hua Book Company, 1985:57. 